\title{
РОТАЦИОННЫЙ РЕЖИМ ЗЕМЛИ И СЕЗОННЫЕ ОСОБЕННОСТИ ТЕХНОГЕННЫХ СЕЙСМИЧЕСКИХ ПРОЦЕССОВ УРАЛЬСКОГО РЕГИОНА
}

\author{
Л.В. НЕКРАСОВА \\ Горный институт УрО РАН, г. Пермь
}

\begin{abstract}
Аннотация: Геодинамические процессы, происходящие в земной коре, по мнению целого ряда исследователей, являются следствием ротационного режима Земли, т.е. неравномерности суточного вращения Земли вокруг своей оси. Нами впервые был проведен детальный анализ сезонной структуры сейсмических процессов на территории ряда месторождений на различных масштабных уровнях. Это стало возможно благодаря накопленному богатому материалу, который содержат многолетние каталоги сейсмических событий на различных месторождениях.

В данной статье представлены исследования сезонных особенностей техногенных сейсмических процессов на примере Североуральского бокситового месторождения. Были проанализированы более 6 тысяч самых крупных сейсмических событий с энергией от 10 тыс. Дж до 1,26 млрд. Дж за 24 летний период с 1994 по 2017 год. В результате исследований было выявлено, что реализация событий для Североуральского бокситового месторождения происходит по двум временным законам. Выделены циклы активизации событий, очаги которых с высокой корреляционной связью реагируют на различные компоненты скорости вращения Земли. Определены периоды времени наиболее высокой сейсмической активности для данного месторождения.
\end{abstract}

Ключевые слова: сезонная структура сейсмического процесса, неравномерности суточного вращения Земли, сейсмичность.

В настоящее время известно, что сейсмичность обладает определенной организацией структурой, проявляющейся в неравномерности распределения сейсмических событий в пространстве - времени - энергии. Ей присущи фрактальные свойства, отражающие статистическое самоподобие сейсмического процесса на различных масштабных уровнях.

По мнению целого ряда исследователей, геодинамические процессы, происходящие в земной коре, являются следствием ротационного режима Земли, т.е. неравномерности суточного вращения Земли вокруг своей оси.

Нами выполнены исследования сезонных особенностей техногенных сейсмических процессов на различных месторождениях, расположенных в Уральском регионе. В данной статье рассмотрены результаты анализа на примере Североуральского бокситового месторождения.

В 30-е годы прошлого века в 500-х км от Екатеринбурга было открыто крупное месторождение бокситов. Для его разработки создали специальное предприятие - Североуральский бокситовый рудник. В настоящее время рудник является ведущим предприятием по добыче бокситов. На шахтах Североуральска добывается более $70 \%$ от всех бокситов в России. СУБР сегодня - это четыре мощных действующих шахты: «Черемуховская», «Кальинская», «Ново-Кальинская», «Красная Шапочка» (№14 и №15). В 2015 году была введена в эксплуатацию самая глубокая шахта России - «Черёмуховская-Глубокая», которая вошла в пятерку наиболее глубоких шахт мира. Глубина её выработки составляет 1550 метров. Здесь планируют добывать более 1 миллиона тонн боксита в год. Именно этот объект должен обеспечить страну алюминием на 40 лет вперед, что является ее стратегическим запасом.

Первые ощутимые динамические проявления горного давления на шахтах Североуральского бокситового бассейна (СУБР) были отмечены в начале 1970-х годов. За 20-летний период с 1970 по 1990 годы на шахтах СУБР было зафиксировано также около половины всех горных ударов на рудниках бывшего СССР. Почти вся возбужденная сейсмичность СУБР была сконцентрирована в пределах двух шахт - № 14 и № 15. Ежегодно здесь регистрируется около тысячи сейсмических событий, наиболее крупное из которых имеет энергию $10^{9}$ Дж.

На данном месторождении в течение четверти века проводились непрерывные сейсмологические наблюдения. Были сформированы уникальные базы сейсмологических данных. Наличие таких баз делает этот горнодобывающий бассейн уникальным объектом 
для изучения особенностей сейсмического режима в условиях сильного техногенного воздействия на недра и для анализа возможного влияния различных природных факторов.

По Североуральскому бокситовому месторождению нами были проанализированы более 6 тысяч самых крупных динамических явлений с энергией от 10 тыс. Дж до 1,26 млрд. Дж за 24 летний период с 1994 по 2017 год.

Вся сейсмичность разделена на две составляющие - «условно природная» и «условно техногенная». Всплески сейсмичности в течение суток, связанные с трехсменной работой на СУБР, положены в основу разделения сейсмоактивности на две компоненты. События, приуроченные к максимумам отнесены к «условно техногенным», а события, произошедшие в оставшееся время - к «условно природным».

Благодаря накопленному богатому материалу, который содержат многолетние каталоги сейсмических событий, впервые был проведен детальный анализ сезонной структуры сейсмических процессов на территории месторождения на различных масштабных уровнях.

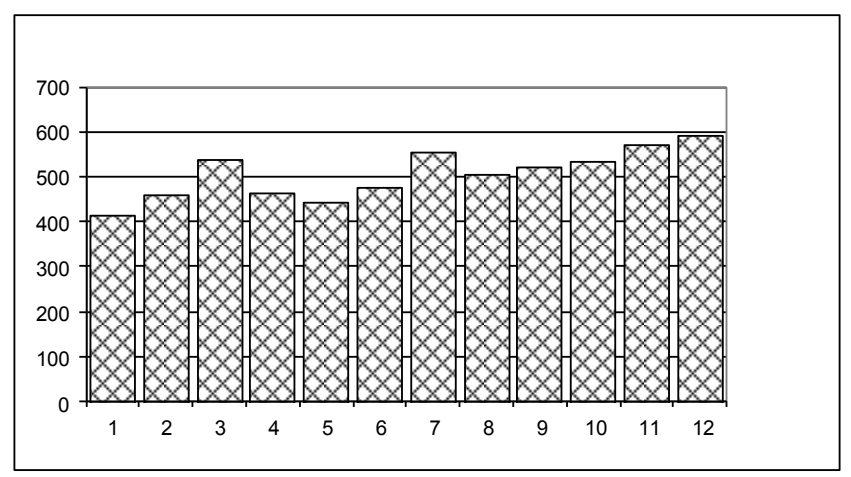

Рис. 1. Распределение в течение года 6060 динамических явлений на шахтах Североуральского бокситового рудника за период с 1994 по 2017 год

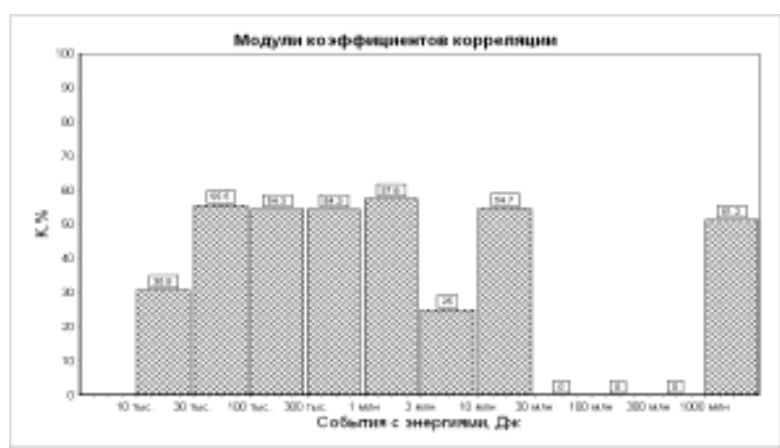

Рис. 2. Модули коэффициентов корреляции функции сезонных изменений скорости вращения Земли с динамическими явлениями различного энергетического уровня Североуральского бокситового месторождения за период с 1994 по 2017 год

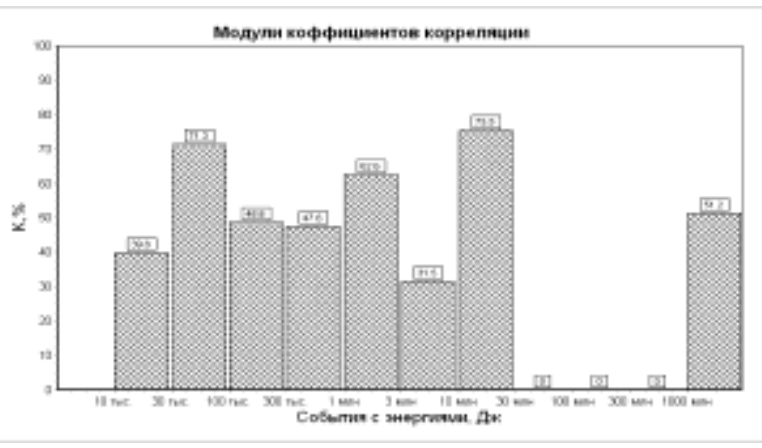

Рис. 3. Модули коэффициентов корреляции функции сезонных изменений скорости вращения Земли с «условно техногенными» динамическими явлениями различного энергетического уровня на шахтах Североуральского бокситового месторождения за период с 1994 по 2017 год

Весь диапазон динамических явлений на СУБРе от 10 тыс. до 1.3 млрд. Дж (рис.1) реагирует на сезонные вариации скорости вращения Земли (рис.2).

Для «техногенной» составляющей коэффициенты корреляций еще более возрастают (рис.3).

На данном месторождения выделено два энергетических диапазона микросейсмических событий по-разному реагирующих на сезонные изменения скорости вращения Земли.

События, с энергией менее 1 млн. Дж, реагируют на годовую составляющую изменений скорости (рис. 4). События, с энергией более 1 млн. Дж - на полугодовую составляющую (рис. 5). Корреляционная связь и в том, и в другом случаях отрицательная. 


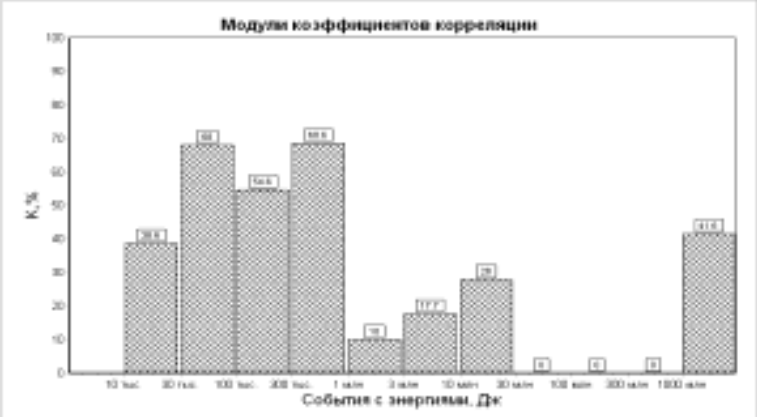

Рис. 4. Модули коэффициентов корреляции годовой составляющей сезонных изменений скорости вращения Земли и динамическими явлениями различного энергетического уровня Североуральского бокситового месторождения за период с 1994 по 2017 год

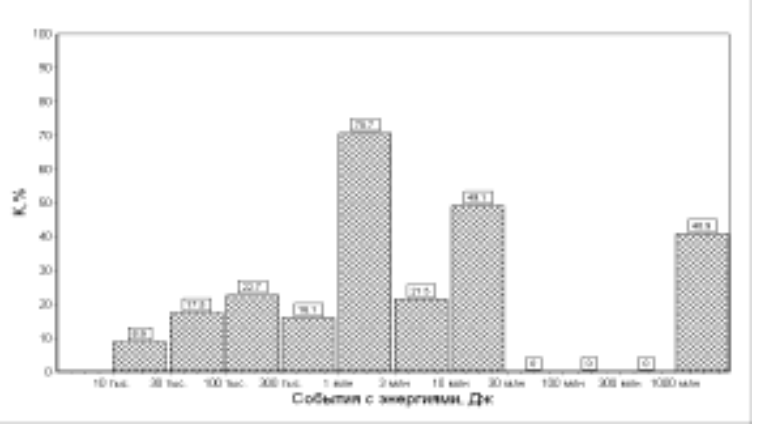

Рис. 5. Модули коэффициентов корреляции полугодовой составляющей сезонных изменений скорости вращения Земли и динамическими явлениями различного энергетического уровня Североуральского бокситового месторождения за период с 1994 по 2017 год

События более высоких энергий от 1 млн. Дж до 1,3 млрд. Дж также реагируют на изменения ускорения вращения Земли (рис.6).

На Североуральском месторождении на лицо реализация событий по двум временным законам. Цикл активизации событий, очаги которых реагируют на годовую компоненту скорости вращения, отмечен с июля по декабрь. Наибольшее их число произошло во вторую половину года. Активное проявление событий, связанных с полугодовой компонентой скорости имеет место в марте - апреле и в октябре - ноябре, то есть в периоды, когда скорость вращения Земли имеет минимальные значения. С февраля по апрель и с октября по декабрь месяц имело место в 1,6 раза больше событий второй группы, чем в оставшуюся половину года.
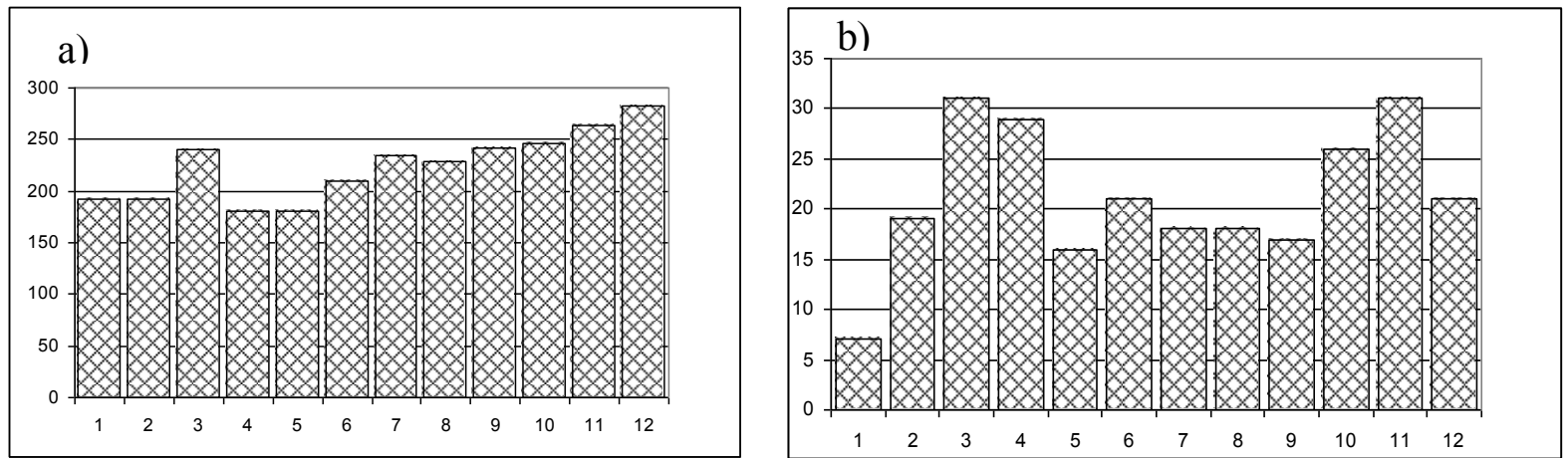

Рис. 7. Сезонные распределение динамических явлений первой группы (а) (менее 1млн. Дж) и второй группы ( b) (более 1 млн. Дж) Североуральского

бокситового месторождения 
Таким образом, выполненные исследования свидетельствуют о существовании выраженной сезонной структуры микросейсмического процесса. Сравнение распределений сейсмичности в течение года с сезонными вариациями скорости суточного вращения Земли показывает, что сейсмическая активность существенно возрастает в периоды замедления скорости. Эффект неравномерного вращения Земли наиболее рельефно проявляется для событий определенных энергетических уровней. Для каждого месторождения характерен свой фазовый сдвиг для циклов активизации микросейсмического процесса относительно сезонных изменений скорости вращения Земли.

\title{
БИБЛИОГРАФИЧЕСКИЙ СПИСОК
}

1. Киселев В.М. Неравномерность суточного вращения Земли / отв. ред. Ю.Д. Калинин. - Новосибирск: Наука, 1980. - С. 160.: ил.

\section{ОСОБЕННОСТИ КОРРЕЛЯЦИИ ОТРАЖАЮЩИХ ГОРИЗОНТОВ СОЛЯНОЙ ТОЛЩИ}

\author{
А.И. НИКИФОРОВА \\ Горный институт УрО РАН, г. Пермь
}

\begin{abstract}
Аннотация: Основной особенностью, затрудняющей интерпретацию данных сейсморазведочных исследований на территории Верхнекамского месторождения, является значительная лито-фациальная изменчивость строения соляной и надсоляной толщ. При этом, сейсмогеологические характеристики разреза меняются как по вертикали, так и по латерали. Эти факторы существенно осложняют привязку и прослеживание опорных отражающих границ. Поэтому анализ достоверности и точности полученных результатов является необходимым этапом интерпретации. Объективная оценка материалов сейсморазведочных исследований возможна по результатам последующего бурения геологоразведочных скважин и проходки горных выработок. Выполненный анализ позволяет выявить возможные причины погрешностей определения глубин залегания отражающих горизонтов.
\end{abstract}

Ключевые слова: Верхнекамское месторождение калийных и магниевых солей, литология, сейсморазведка, сейсмоакустическая модель, погрешность определения глубины.

При интерпретации сейсмических данных необходимо учитывать факторы, не позволяющие отождествлять все особенности волнового поля с особенностями геологического строения. Среди них- условия осадконакопления и постседиментационные преобразования пород. Последние значительно усложняют распределение геоакустических параметров в разрезе, вуалируют сейсмическое изображение. В таких разрезах усложняется пространственное распределение скоростей и других петрофизических параметров, появляются несоответствия геологических и сейсмических границ [2]. Особенно актуальна эта проблема для специфических условий Верхнекамского месторождения. А именно, по причине: малой глубины целевого интервала (до 500 м), тонкослоистой структуры целевых интервалов геологического разреза и существенной латеральной изменчивости их физических параметров.

Согласно результатам скоростного анализа и материалам разведки месторождения выделяется ряд отражающих горизонтов, характеризующих строение соленосного и надсолевого комплексов пород. При построении обобщенной сейсмогеологической модели для определения полярности сейсмической записи, стратиграфической привязки отражений, изучения влияния скоростных неоднородностей разреза учитывались результаты одномерного сейсмического моделирования, выполненного в разные годы. Для решения этих задач расчет синтетических трасс проводился в условиях горизонтально-слоистой среды и вертикально распространяющейся плоской продольной волны. Использовались детальные сейсмоакустические модели с привлечением акустического каротажа (рис. 1). 